\title{
Comparison of Histological Findings and Parathyroid Scintigraphy in Hemodialysis Patients with Secondary Hyperparathyroid Glands
}

\author{
HIDEMI NISHIDA, MASATOSHI ISHIBASHI*, YUJI HIROMATSU**, HAYATO KAIDA*, KENKICHI BABA*, \\ IKUYO MIYAKE**, HIROFUMI IKEDO, SEIYA KATO***, KEI FUKAMI, SHUJI IIDA AND SEIYA OKUDA \\ Department of Nephrology and Dialysis Unit, Kurume University School of Medicine, Kurume, Fukuoka 830-0011, Japan \\ *Division of Nuclear Medicine and Department of Radiology, Kurume University School of Medicine, Kurume, Fukuoka 830-0011, \\ Japan \\ **Department of Endocrinology and Metabolism, Kurume University School of Medicine, Kurume, Fukuoka 830-0011, Japan \\ ***Department of Pathology, Kurume University School of Medicine, Kurume, Fukuoka 830-0011, Japan
}

\begin{abstract}
To determine the usefulness of parathyroid scintigraphy in histological estimation for secondary hyperparathyroidism (2HPT) using Tc-99m sestamibi or Tc-99m tetrofosmin. Tc-99m sestamibi (MIBI) and Tc-99m tetrofosmin (Tetro) parathyroid imaging following double-phase study, magnetic resonance imaging (MRI), and ultrasound were performed on 14 patients with 2HPT. All patients underwent parathyroidectomy. The uptake of two tracers in parathyroid areas was compared with the histopathologic findings. Forty-nine parathyroid glands were surgically explored and histologically proven to be hyperplastic. Of these, 42 were diagnosed with nodular type (N-type) hyperplasia, and 7 with diffuse type (D-type) hyperplasia. MIBI and Tetro parathyroid imagings detected 34 and 35 parathyroid glands, respectively. The sensitivity of MIBI was determined to be $76.2 \%(32 / 42)$ for N-type, and 28.6\% (2/7) for D-type. The sensitivity of Tetro was determined to be $78.6 \%$ (33/42) for N-type and $28.6 \%(2 / 7)$ for D-type. The sensitivity of both MIBI and Tetro was significantly higher for N-type than for D-type, $76.2 \%(32 / 42)$ vs. $28.6 \%(2 / 7)$ in MIBI, P = 0.022 ; $78.6 \%(33 / 42)$ vs. $28.6 \%(2 / 7)$ in Tetro, $\mathrm{P}=0.015$. The sensitivity of MRI was determined to be $76.2 \%(32 / 42)$ for N-type and $42.9 \%$ (3/7) for D-type, and the sensitivity of ultrasound was 71.4\% (30/42) for N-type and 71.4\% (5/7) for D-type. There was no significant difference in the sensitivity of MRI or ultrasound between N-type and D-type. The uptake ratios of MIBI and Tetro were also greater for N-type than for D-type. The detectability of both MIBI and Tetro was greater for N-type than for D-type. Tc-99m MIBI or Tc-99m Tetro parathyroid scintigraphy therefore may be used clinically to distinguish N-type from D-type parathyroid gland hyperplasia.
\end{abstract}

Key words: Parathyroid scintigraphy, Tc-99m sestamibi; Tc-99m tetrofosmin, Chronic hemodialysis, Secondary hyperparathyroidism

(Endocrine Journal 52: 223-228, 2005)

METABOLIC bone disease, such as renal osteodystrophy, is one of the major complications in patient undergoing maintenance hemodialysis. One of the primary contributing factors underlying metabolic bone is secondary hyperparathyroidism, which results from a

Received: June 14, 2004

Accepted: December 6, 2004

Correspondence to: Hidemi NISHIDA, M.D., Department of Nephrology and Dialysis Unit, Kurume University School of Medicine, 67 Asahimachi, Kurume, Fukuoka 830-0011, Japan decreased serum concentration of $1,25(\mathrm{OH})_{2} \mathrm{D}_{3}$ and subsequent hypocalcemia and hyperphosphatemia. The decrease in vitamin D receptors is thought to be related to the progression of 2HPT. The efficacy of high dose calcitriol pulse therapy depends on the density of vitamin $\mathrm{D}$ receptors in the parathyroid glands. In cases showing a poor response to vitamin D pulse therapy, parathyroid surgery may be indicated for persistent hypercalcemia, progressive extraskeletal calcification, severe progressive skeletal pain or fractures, and the appearance of calciphylaxis or intractable pruritus [1]. 
Preoperative imaging techniques include ultrasonography, computed tomography (CT), magnetic resonance imaging (MRI), and Tl-201/Tc-99m pertechnetate (T1/Tc) or Tl-201/I-123 subtraction scintigraphy [3-8]. In 1989, a new approach utilizing myocardial imaging with radiopharmaceutical Tc-99m sestamibi (MIBI) was reported for the localization of parathyroid glands of the normoxic and ectopic regions $[9,10]$. Several investigators have confirmed the usefulness of this technique in identifying abnormal parathyroid glands either alone [11-14], or with subtraction imaging [15]. In 1995, we reported, for the first time, that Tc-99m tetrofosmin (Tetro) could also be used for parathyroid imaging [16]. The similarity of Tc-99m tetrofosmin to sestamibi in its myocardial behavior as well as preliminary evidence confirming its localization in abnormal parathyroid tissue, suggested that a comparison of Tclabeled agents in patients with known parathyroid disease would be worthwhile $[17,18]$. The purpose of the present study was to clarify the clinical significance of the uptake of these parathyroid tracers for distinguishing nodular type hyperplasia from diffuse type hyperplasia in hemodialysis patients. The distinction is extremely important for the selection of a suitable therapeutic scheme.

\section{Materials and Methods}

\section{Study population}

We evaluated 14 patients ( 8 men and 6 women, ranging in age from 37 to 61 years, mean age 47 years) with 2HPT due to chronic renal failure treated with hemodialysis. The etiology of renal failure in the uremic patients was diagnosed as chronic glomerulonephritis. The uremic patients had been on hemodialysis for $132 \pm 48$ months and were dialyzed three times per week. All patients failed to respond to vitamin D therapy or vitamin D pulse therapy and underwent parathyroid surgery. Their clinical characteristics at the time of parathyroidectomy are shown in Table 1. Parathyroidectomy was performed within one month after radionuclide imaging, the location, weight, and histopathologic findings were recorded. The parathyroid glands of all patients were studied through imaging with ultrasonography, MRI, and radionuclide techniques (MIBI and Tetro), and the locations, weight, and histopathologic findings of the excised glands were
Table 1. Clinical characteristics of the patients with secondary hyperparathyroidism

\begin{tabular}{rcccccc}
\hline Case & Gender & $\begin{array}{c}\text { Age } \\
\text { (year) }\end{array}$ & $\begin{array}{c}\text { Duration of } \\
\text { HD (months) }\end{array}$ & $\begin{array}{c}\text { intact PTH } \\
(\mathrm{pg} / \mathrm{ml})\end{array}$ & $\begin{array}{c}\mathrm{Ca} \\
(\mathrm{mg} / \mathrm{dl})\end{array}$ & $\begin{array}{c}\mathrm{P} \\
(\mathrm{mg} / \mathrm{dl})\end{array}$ \\
\hline 1 & $\mathrm{~m}$ & 49 & 122 & 1100 & 10.2 & 8.7 \\
2 & $\mathrm{f}$ & 46 & 74 & 1758 & 9.1 & 7 \\
3 & $\mathrm{f}$ & 45 & 152 & 2399 & 11.1 & 7.5 \\
4 & $\mathrm{f}$ & 37 & 150 & 503 & 11.1 & 8.6 \\
5 & $\mathrm{f}$ & 49 & 173 & 608 & 10.9 & 7.6 \\
6 & $\mathrm{~m}$ & 61 & 147 & 1198 & 10.2 & 4.6 \\
7 & $\mathrm{~m}$ & 30 & 100 & 1475 & 9.8 & 4.9 \\
8 & $\mathrm{f}$ & 53 & 150 & 1432 & 8.9 & 5.5 \\
9 & $\mathrm{~m}$ & 54 & 65 & 672 & 11.8 & 7 \\
10 & $\mathrm{~m}$ & 47 & 140 & 963 & 10.6 & 5.4 \\
11 & $\mathrm{~m}$ & 47 & 242 & 1400 & 9.5 & 5.7 \\
12 & $\mathrm{~m}$ & 45 & 70 & 1013 & 9.9 & 6.1 \\
13 & $\mathrm{~m}$ & 21 & 103 & 1421 & 9.3 & 8.2 \\
14 & $\mathrm{~m}$ & 58 & 171 & 773 & 10.1 & 4.7 \\
\hline
\end{tabular}

HD, hemodialysis; PTH, parathyroid hormone; m, male; f, female

recorded for each patient. Informed consent was obtained from each patient as part of the protocol approved by the Institutional Clinical Subpanel on Human Studies at our university.

\section{Tc-99m sestamibi and Tc-99m tetrofosmin parathyroid imaging}

Imagings with Tc-99m MIBI and Tc-99m Tetro were performed within 3 or 4 weeks before parathyroidectomy. Each agent was administered intravenously (about $600 \mathrm{MBq}$ sestamibi, Dupont, UK, and about $740 \mathrm{MBq}$ tetrofosmin, Amersham International, Bucks, UK). Anterior images of the neck were recorded with a small field-of-view camera (GCA-10A, Toshiba, Tokyo, Japan) at 10 minutes and 2-3 hours after injection both in analog form on film, and digitally $(256 \times 256)$ on a dedicated computer system (Toshiba 550U, Tokyo, Japan) equipped with a low energy, general-purpose parallel-hole collimator. Each image was recorded for 10 minutes with a $15 \%$ window centered on the $140 \mathrm{keV}$ photopeak; approximately 500,000 counts were recorded for each image. In addition, a large field-of-view gamma camera and computer system (26001 and RW 3000, Hitachi, Tokyo, Japan), equipped with a lowenergy, high resolution parallel hole collimator was used to record concomitant anterior images of the mediastinum at about 1 hour after radiotracer injection. Two observers, unaware of the patients' clinical findings or of the results of MRI, evaluated the scintigrams 
for the presence of abnormal increased uptake in the region of the thyroid bed or mediastinum. Early and late Tc-99m MIBI and Tc-99m Tetro images were compared, and scans were scored positive or negative for parathyroid localization and the early images were categorized as slight or intense uptake compared to thyroid uptake on the late images. The initial image, acquired at 10 minutes after radiotracer injection, was referred to as the "thyroid phase" image, and the second image at 1 hour and the third image at 3 hours were referred to as the "parathyroid phase" image following the modified imaging technique previously described by Taillefer et al. [11]. Tc-99m MIBI images were reviewed independently from the Tc-99m Tetro data and the results were compared. Where discrepancies occurred, the evaluators reached a consensus opinion. Areas of persistent increased uptake recorded at 13 hours after the injection were considered to represent parathyroid tissue. Regions of interest (ROIs) were identified and the parathyroid gland/normal thyroid tissue activity ratio (the $\mathrm{P} / \mathrm{T}$ uptake ratio) in the late parathyroid images was calculated [11].

\section{Histopathologic methods}

Resected parathyroid tissues were fixed in $10 \%$ formalin for 24 hours. After dehydration with $70-100 \%$ ethanol dilutions, the tissues were embedded in paraffin wax and $4 \mu \mathrm{m}$ sections were stained with hematoxylin and eosin. Based on laboratory findings, all lesions were suspected to be secondary hyperplasia, and this diagnosis was later confirmed both by gross findings and through histological characterization under conventional light microscopy [19]. These lesions were variously distributed in more than one parathyroid gland and were not identified as adenoma [20]. The lesions were divided into two categories: diffuse type (D-type), which shows a predominantly diffuse sheet-like pattern of hyperplasia with normal lobular composition, and nodular type (N-type), which shows at least one nodular proliferation pattern wellencapsulated by fibrous tissue and fat cell-free accumulation of parenchymal cells [21]. Asymmetric arrangement of the tubulus, an increased number of oxyphil cells, and irregular nuclear morphology were also accounted for the N-type [19].
Table 2. Detectablity of abnormal parathyroid glands by various modalities

\begin{tabular}{|c|c|c|c|c|c|c|c|c|}
\hline & \multicolumn{2}{|c|}{ MIBI } & \multicolumn{2}{|c|}{ Tetro } & \multicolumn{2}{|c|}{ MRI } & \multicolumn{2}{|c|}{ Ultrasound } \\
\hline & $(+)$ & $(-)$ & $(+)$ & $(-)$ & $(+)$ & $(-)$ & $(+)$ & $(-)$ \\
\hline Nodular & 32 & $10 *$ & 33 & $9 * *$ & 32 & 10 & 30 & 10 \\
\hline Diffuse & 2 & 5 & 2 & 5 & 3 & 4 & 5 & 2 \\
\hline
\end{tabular}

MIBI, Tc-99m senstamibi; Tetro, Tc-99m tetrofosmin; MRI, magnetic resonance imaging.

nodular, nodular type hyperplasia; diffuse, diffuse type hyperplasia. ${ }^{*} P=0.022,{ }^{*} P=0.015$ (Fisher's exact probability test)

\section{Statistics}

All quantitative data were expressed as the mean \pm standard deviation. Statistical analysis was performed using the Mann-Whitney test, the chi-square test or Fisher's exact probability test, as appropriate. A $p$ value of $<0.05$ was considered significant.

\section{Results}

Forty-nine parathyroid glands were surgically explored and histologically proven to be hyperplastic. Of these, 42 showed nodular type (N-type) hyperplasia, and 7 showed diffuse type (D-type) (Fig. 1). MIBI and Tetro parathyroid imagings detected 34 and 35 parathyroid glands, respectively (Table 2 ). The sensitivity of MIBI was determined to be $76.2 \%(32 / 42)$ for $\mathrm{N}$ type and $28.6 \%(2 / 7)$ for D-type. The sensitivity of Tetro was determined to be $78.6 \%$ (33/42) for N-type and $28.6 \%(2 / 7)$ for D-type. The sensitivity of both MIBI and Tetro was significantly higher for N-type than for D-type, $76.2 \%(32 / 42)$ vs. $28.6 \%(2 / 7)$ in MIBI, $\mathrm{P}=0.022 ; 78.6 \%(33 / 42)$ vs. $28.6 \%(2 / 7)$ in Tetro, $\mathrm{P}=0.015$. The sensitivity of MRI was determined to be $76.2 \%(32 / 42)$ for N-type and $42.9 \%$ (3/7) for D-type, and the sensitivity of ultrasound was $71.4 \%$ (30/42) for N-type and 71.4\% (5/7) for D-type. There was no significant difference in the sensitivity of MRI or ultrasound between N-type and D-type. The uptake ratios of MIBI and Tetro were also greater for N-type than for D-type (Fig. 2).

\section{Discussion}

With the progression of chronic renal insufficiency, 


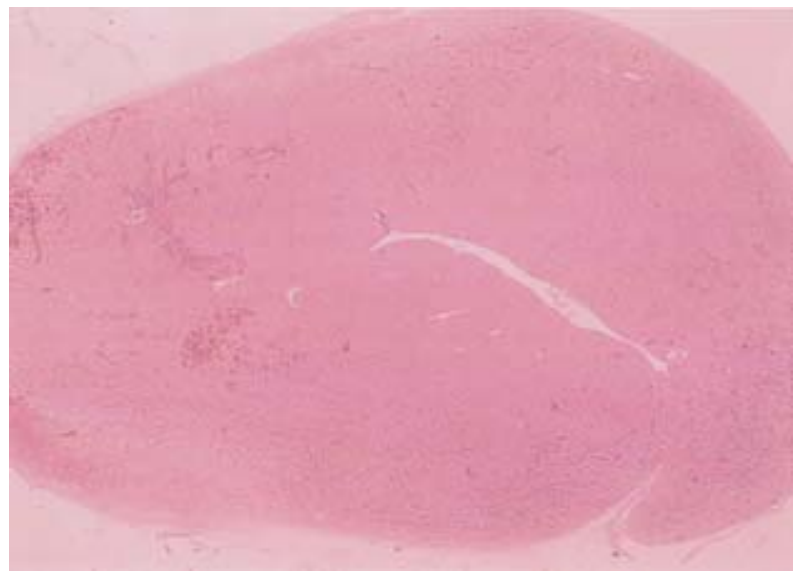

A

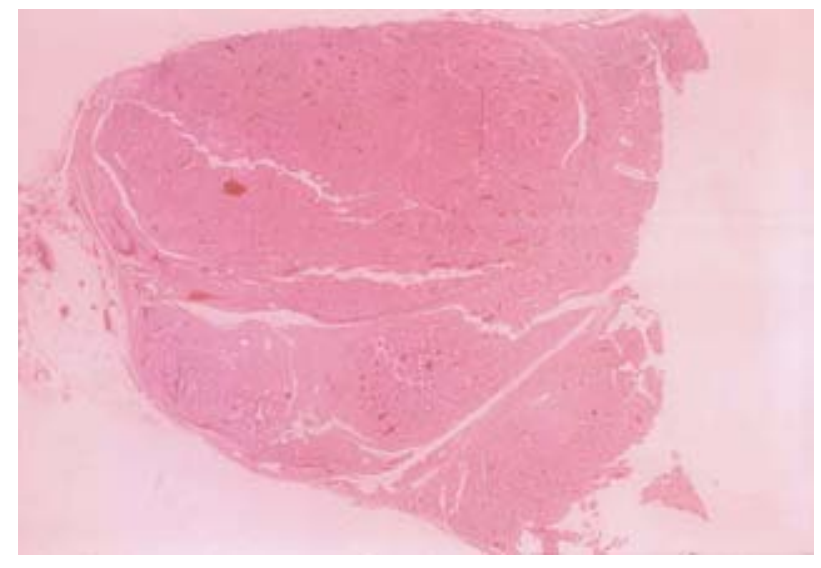

B

Fig. 1. Diffuse type (A) and nodular type (B) of parathyroid hyperplasia in secondary hyperparathyroidism (Hematoxylin-Eosin staining, $\times 50$ ).

the total weight of the parathyroid glands may increase considerably associated with the elevation of serum PTH and abnormal set point for calcium-regulated PTH secretion. The degree of the enlargement correlates with the duration and severity of renal function impairment $[22,23]$. The histopathological findings of parathyroid glands associated with chronic renal failure show that parathyroid glands change progressively throughout the development of the disease [24]. The earliest change is a decrease in the number of stromal fat cells and their partial replacement by widened cords and nests of chief cells. This type of lesion may progress into D-type hyperplasia. The advanced stages are characterized by nodular proliferation of chief cells and oncocytes [23]. Considering that all 14 patients in

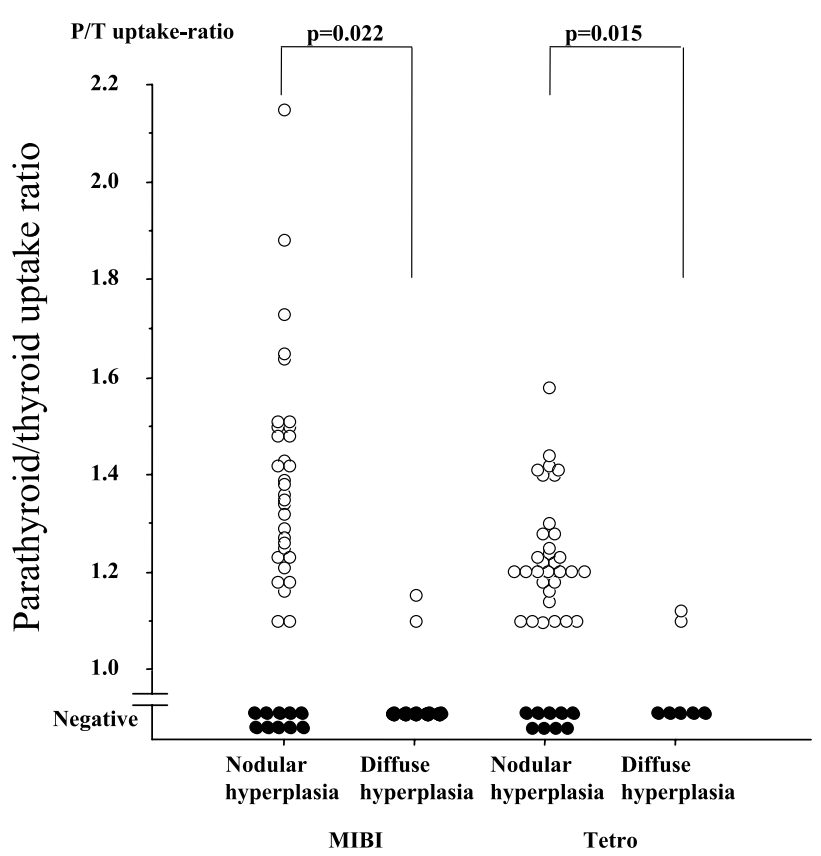

Fig. 2. Tc-99mMIBI and Tc-99m tetrofosmin scintigraphy. The uptake of radiotracers in the parathyroid region was assessed as ratio to that in thyroid region. The uptake ratios of MIBI and Tetro were significantly greater for N-type than for D-type (Mann-Whitney test).

this study had a long history of hemodialysis, the majority of the parathyroidal lesions were naturally recognized as the N-type. N-type hyperplasia is usually present in patients with higher concentrations of intact PTH and the more severe bone symptoms [2]. Fukuda et al. [2] reported that the clinically severe N-type parathyroid hyperplasia was associated with a reduced number of vitamin $\mathrm{D}$ receptors per unit of gland section compared with the mild D-type gland hyperplasia. Because the density of calcium sensing receptors is lower in the N-type glands, it is apparent that vitamin D receptor abnormalities in the parathyroid glands of patients with uremia play a role in the abnormal set point for calcium-regulated PTH secretion. This may also explain the failure of vitamin D pulse therapy for $\mathrm{N}$-type hyperplasia in hemodialysis patients. Indeed, the efficacy of high dose calcitriol therapy depends, to a certain degree, on the vitamin D receptor density in the parathyroid and on the size of the parathyroid. Therefore, it would be useful to be able to distinguish $\mathrm{N}$-type hyperplasia from D-type hyperplasia with simple clinical techniques.

MIBI and Tetro scintigraphies have been proposed as preoperative methods of locating parathyroid ade- 
noma in primary hyperparathyroidism [11, 26-28]. In patients with 2HPT, however, the efficacy of these techniques has been reported to be less $[11,26]$. The relationship between the uptake of these tracers and the subtypes of hyperplasia remains unclear. The present study revealed that both MIBI and Tetro provide significantly better localization for N-type hyperplasia than for D-type hyperplasia. In many cases, since Ntype parathyroid glands are resistant to vitamin $\mathrm{D}$ pulse therapy. MIBI and Tetro parathyroid imaging may help clinicians to determine the appropriateness of vitamin D pulse therapy. The histological significance of radionuclide uptake in MIBI or Tetro parathyroid scintigraphy following double-phase study is still unknown in the field of hemodialysis $[11,16]$. We previously reported that MIBI uptake by parathyroid glands did not reflect the rate of mitochondria-rich cells [29]. Gogusev et al. [30] recently reported that the number of calcium sensors on the surface of N-type hyperplastic cells was lower than that found in D-type cells. Tc-MIBI is sequestered inside the cytoplasm and mitochondria, and its degree of cellular incorporation and retention depends on the electric potential generated through the cellular and mitochondrial membrane [31]. However, the actual mechanism of radiotracer captation in the hyperplastic parathyroid tissue has yet to be completely understood [32]. Nevertheless, we demonstrated for the first time the positive association between Tc-MIBI and Tetro scintigraphy and subtypes of hyperplasia. Both MIBI and Tetro scitigraphy may be useful to distinguish N-type from D-type hyperplasia. Although the precise mechanism of the uptake or kinetics of MIBI and Tetro has not been clarified, those modalities may provide potential tools for the prediction of the therapeutic outcome in 2HPT. Future studies are necessary to investigate whether Tc-99m MIBI and Tetro parathyroid imagings using double-phase techniques are useful in planning therapy for patients with 2HPT.

\section{References}

1. Tominaga Y (2000) Management of renal hyperparathyroidism. Biomed Pharmacother 54 (Suppl 1): 25-31.

2. Fukuda N, Tanaka H, Tominaga Y, Fukagawa M, Kurokawa K, Seino Y (1993) Decreased 1,25dihydroxy vitamin D3 receptor density is associated with a more severe form of parathyroid hyperplasia in chronic uremic patients. J Clin Invest 92: 1436-1443.

3. Krubasack A, Wilson SD, Lawson TL, Kneeland JB, Thorsen MK, Collier BD, HellmanRS, Isitman AT (1989) Prospective comparison of radionuclide, computed tomographic, sonographic, and magnetic resonance localization of parathyroid tumor. Surgery 106: 639-646.

4. Sommer B, Welter HF, Spelsberg F, Scherer U, Lissner J (1982) Computed tomography for localization enlarged parathyroid glands in primary hyperparathyroidism. J Comput Assist Tomography 6: 521-526.

5. Kang YS, Rosen K, Clark OH, Higgins CB (1993) Localization of abnormal parathyroid glands of the mediastinum with MR imaging. Radiology 189: 137141.

6. Ferlin G, Borsato N, Camerani M, Conte N, Zotti D (1983) New prospective in locating enlarged parathyroids by Technetium-Thallium subtraction scan. J Nucl Med 13: 522-527.

7. Sandrock D, Merino MJ, Norton JA, Neumann RD (1990) Parathyroid imaging by Tc/Tl scintigraphy. Eur
J Nucl Med 16: 607-613.

8. Fine EJ (1987) Parathyroid imaging: its current status and future role. Semn in Nucl Med 17: 350-359.

9. Iskandrian AS, Heo J, Kong B, Lyons E, Marsch S (1989) Use of technetium-99m-isonitrile (RP-30A) in assessing left ventricular perfusion and function at rest and exercise in coronary artery disease and comparison with coronary arteriography and exercise thallium-201 SPECT images. Am J Cardiol 64: 270-275.

10. Coakley AJ, Kettle AG, Wels CP, O'Dohherty MJ, Collins REC (1989) Tc-99m sestamibi — new agent for parathyroid imaging. Nucl Med Comm 10: 791794.

11. Taillefer R, Boucher Y, Potvin C, Lambert R (1992) Detection and localization of parathyroid adenoma in patients with hyperparathyroidism using a single radionuclide imaging procedure with Technetium-99m sestamibi (double-phase study). J Nucl Med 33: 18011807.

12. O'Doherty MJ, Kettle AG, Wells P, Collitis REC, Coakley AJ (1992) Parathyroid imaging with Technetium-99m sestamibi: preoperative localization and tissue uptake studies. J Nucl Med 33: 313-318.

13. Geatti O, Shapiro B, Orsolon PG, Proto G, Guerra UP, Antonucci F, Gasparini D (1994) Localization of parathyroid enlargement: experience with Technetium-99m methoxyisobutylisonitrile and Thallium-201 scintigraphy, ultrasonography and computed tomography. Eur $J$ 
Nucl Med 21: 17-22.

14. Lee VS, Wilkinson RH, Leight GS, Coogan AC, Coleman RE (1995) Hyperparathyroidism in high-risk surgical patients: evaluation with double-phase Technetium-99m sestamibi imaging. Radiology 197: 627633.

15. Jeanguillaume $C$, Urena $P$, Hindie $E$, Prieur $P$, Petrover M, Menoyo-Calonge V, Janin A, Chiappini-Briffa D, Melliere D, Boulahdour H, Galle P (1998) Secondary hyperparathyroidism: detection with I-123-Tc-99mSestamibi subtraction scintigraphy versus US. Radiology 207: 207-213.

16. Ishibashi M, Nishida $\mathrm{H}$, Kumabe $\mathrm{T}$, Morita $\mathrm{S}$, Matoba F, Nomura G, Hayabuchi N (1995) Tc-99m tetrofosmin: A new diagnostic tracer for parathyroid imaging. Clin Nucl Med 20: 902-905.

17. Ishibashi M, Nishida H, Strauss HW, Kojima K, Fujito H, Watanabe J, Hiromatsu Y, Hayabuchi N (1997) Localization of parathyroid glands using Tc-99m tetrofosmin imaging. J Nucl Med 38: 706-711.

18. Ishibashi $\mathrm{M}$, Nishida $\mathrm{H}$, Hiromatsu $\mathrm{Y}$, Kojima K, Tabuchi E, Hayabuchi N (1998) Comparison of Tc99m MIBI, Tc-99m tetrofosmin, ultrasound and MRI for localization of abnormal parathyroid glands. $J \mathrm{NuCl}$ Med 39: 320-324.

19. Rosai J, Ackerman LV (1996) Ackerman's Surgical Pathology. 10. Parathyroid glands, 7th ed. Mosby Co., St. Louis, 574-576.

20. Ghandur-Mnaymneh L, Kimura N (1984) The parathyroid adenoma: A histologic definition with a study of 172 cases of primary hyperparathyroidism. $\mathrm{Am} \mathrm{J}$ Pathol 115: 70-83.

21. Tominaga $Y$, Tanaka $Y$, Sato K, Numano M, Uchida K, Falkmer U, Grimelius L, Johansson H, Takagi H (1992) Recurrent renal hyperparathyroidism and DNA analysis of autografted parathyroid tissue. World $J$ Surg 16: 595-603.

22. Malmaeus J, Grimelius L, Johansson H, Akerstrom G, Ljunghall S (1984) Parathyroid Parathyroid pathology in hyperparathyroidism secondary to chronic renal failure. Scand J Urol Nephrol 18: 157-166.

23. Tominaga Y, Takagi H, Suzuki H, Kondo T (1985)
Histopathological study of parathyroid gland in renal hyperparathyroid tissue. J Jpn Surg Soc 86: 630-639.

24. Roth SI, Marshall RB (1969) Pathology and ultrastructure of the human parathyroid glands in chronic renal failure. Arch Intern Med 124: 397-407.

25. Delellis RA (1993) Tumors of the parathyroid gland. Atlas of Tumor Pathology, 3rd Series, Fascicle 6. Armed Forces Institute of Pathology, Washington DC, 85-92.

26. Caixàs $\mathrm{A}$, Bernà $\mathrm{L}$, Piera J, Rigla $\mathrm{M}$, Matius-Guiu $\mathrm{X}$, Farrerons J, Puig-Domingo M (1995) Utility of 99mTcsestamibi scintigraphy as a first-line imaging procedure in the preoperative evaluation of hyperparathyroidism. Clin Endocrinol 43: 525-530.

27. Sofferman RA, Nathan MH, Fairbank JT, Foster RS, Krag DN (1996) Preoperative technetium Tc-99m sestamibi imaging. Paving the way to minimal-access parathyroid surgery. Arch Otolaryngology Head Neck Surg 122: 369-374.

28. Hiromatsu $Y$, Ishibashi $M$, Nishida $H$, Okuda $S$, Miyake I (2000) Technetium-99m tetrofosmin parathyroid imaging in patients with primary hyperparathyroidism. Internal Med 39: 101-106.

29. Ishibashi M, Nishida H, Okuda S, Suekane S, Hayabuchi N (1998) Localization of parathyroid glands in haemodialysis patients using Tc-99m sestamibi imaging. Nephron 78: 48-53.

30. Gogusev J, Duchambon P, Hory B, Giovannini M, Goureau Y, Sarfati E, Drueke TB (1997) Depressed expression of calcium receptor in parathyroid gland tissue of patients with hyperparathyroidism. Kidney Int 51: 328-336.

31. Chiu ML, Kronauge JF, Piwnica-Worms D (1990) Effect of mitochondrial and plasma membrane potentials on accumulation of hexakis (2-methoxyisobutylisonitrile) technetium (I) in cultured mouse fibroblasts. J Nucl Med 31: 1646-1653.

32. Ambrosoni $P$, Heuguerot $C$, Olaizola Acuna G, Fajardo L, Petraglia A, Caorsi H, Lopez J, Kurdian M, Jorgetti V, Aznarez A (1998) Can we use 99mTc-MIBI in functional studies of the parathyroid gland? Nephrol Dial Transplant 13 (Suppl 3): 33-36. 